\title{
Assessment of Intracardiac and Extracardiac Anomalies in Patients with Various Types of Pulmonary Atresia by Low-dose Dual-source Computed Tomography
}

\author{
Wen-lei Qian \\ West China Hospital of Sichuan University \\ Xin-zhu Zhou \\ Chengdu Women's and Children's Central Hospital \\ Ke Shi \\ West China Hospital of Sichuan University \\ Li Jiang \\ West China Hospital of Sichuan University \\ Xi Liu \\ Peking University Cancer Hospital \\ Li-ting Shen \\ West China Hospital of Sichuan University \\ Zhi-gang Yang ( $\square$ yangzg666@163.com ) \\ West China Hospital of Sichuan University
}

\section{Research Article}

Keywords: Pulmonary atresia, complex congenital heart diseases, low dose, dual-source computed tomography, transthoracic echocardiography

Posted Date: July 28th, 2021

DOI: https://doi.org/10.21203/rs.3.rs-712404/v1

License: (c) (1) This work is licensed under a Creative Commons Attribution 4.0 International License. Read Full License 


\section{Abstract}

Background: pulmonary atresia (PA) is a group of heterogeneous complex congenital heart disease which need more than one study modality to get correct diagnoses. This study aims to investigate the diagnostic power of low-dose dual-source computed tomography (DSCT) for all intracardiac and extracardiac anomalies in patients with PA compared with transthoracic echocardiography (TTE).

Materials and methods: This retrospective study enrolled 73 patients and divided them into three groups according to their main diagnosis. All associated malformation and clinical information, including treatments, were recorded and compared among the three groups. The diagnostic power of DSCT and TTE on all associated anomalies were compared. The surgical index (McGoon ratio, pulmonary arterials index (PAI), and total neopulmonary arterial index) and radiation dose were calculated on the basis of DSCT.

Results: Of the patients, 29, 29, and 15 were divide into the groups of PA with ventricular septal defect (VSD), PA with VSD and major aortopulmonary collateral arteries, and PA with other major malformations, respectively. Consequently, 178, 144, and 12 intracardiac, extracardiac, and other major anomalies were diagnosed, respectively. Moreover, DSCT showed a better diagnostic performance in extracardiac anomalies (137 vs $100, p=0.000$ ), whereas TTE could diagnose intracardiac anomalies better (158 vs $134, p=0.001)$. The McGoon ratio, PAl, and treatment methods were significantly different among the three groups ( $p=0.027, p=0.035$, and $p=0.041$, respectively).

Conclusion: More than one imaging modality should be used to make a correct diagnosis when clinically suspecting PA. DSCT is superior to TTE in diagnosing extracardiac anomalies and could be used to roughly calculate surgical indices to optimize treatment strategy.

\section{Introduction}

Pulmonary atresia (PA) is identified as a group of heterogeneous congenital heart disease (CHD) whose most important feature is the lack of continuity between the pulmonary arteries and the ventricle. Hence, PA is nearly accompanied by other congenital intracardiac and extracardiac abnormalities (1-3). PA is rare but fatal (4). The survival rate is low without early interventions. Early and late mortality is high in all types of PA (5). In fact, even patients underwent operation, the success rate of surgery is low during the first 30 years after this disease being reported $(6,7)$ However, because of the histologic study of major aortopulmonary collateral arteries (MAPCAs), native pulmonary arteries (NPA), and accumulated knowledge of the blood supply of the lungs $(8,9)$, the survival rate is gradually increasing $(10,11)$. Thus, the condition of NPA, MAPCAs, as well as other anomalies are of the highest importance for surgical strategy and management $(6,12)$.

Transthoracic echocardiography (TTE) is a first-line CHD examination, which could investigate intracardiac anomalies well. However, TTE is not very useful for extracardiac anomalies that are crucial for surgical choices. Cardiac computed tomography is an excellent imaging modality in patients with 
CHD, which could reliably visualize pulmonary arterial supply $(13,14)$. Additionally, dual-source computed tomography (DSCT) broadens its application range because of its lower radiation dose and higher density and spatial resolution (15). However, only a few studies explored the value of DSCT for diagnosing PA focusing only on PA with ventricular septal defect (VSD) and MAPCAs $(16,17)$. PA is not just one type. Hence, this study was divided PA into three groups according to their main diagnosis. Furthermore, the three groups were compared, the DSCT diagnostic power for all intracardiac and extracardiac deformities in PA was analyzed, and the power with TTE was compared.

\section{Materials And Methods Study population}

This study retrospectively enrolled 73 PA patients with various deformations who underwent preoperative DSCT and TTE examinations from June 2012 to December 2020 at the medical center of this study. The inclusion criteria were (1) patients who underwent surgery or cardiovascular angiography (CA) with PA included as the final diagnoses and (2) those who underwent both DSCT and TTE examinations before surgery or CA interventions, with the time interval between the two tests not exceeding 1 month. The exclusion criteria were (1) incomplete medical records and (2) the image quality not meeting the diagnosis requirement. Depending on the main diagnosis, all patients were divided into three groups: (1) patients with PA and ventricular septal defect (PA/VSD), (2) those with PA with VSD and major aortopulmonary collateral arteries (PA/VSD/MAPCAs), and (3) patients with PA with other major malformation (such as PA with single atrium (SA), PA with single ventricle (SV), PA with intact ventricular septum (PA/IVS), and PA with double outlet left/right ventricle).

This study was in line with the principles of the Declaration of Helsinki and approved by the Institutional Ethics Committee of West China Hospital, Sichuan University (Chengdu, Sichuan, China『No.14-163), with a waiver of informed consent due to the retrospective nature. All personal details of any patients have been removed carefully before submission.

\section{Scanning protocol}

All DSCT scans were performed on the same type of machines (Somatom Definition; Siemens Medical Solutions, Forchheim, Germany). Patients aged $>5$ years were trained to hold their breath during the examination. Patients aged $<5$ years and could not cooperate were given short-term sedation (chloral hydrate; $10 \%$ concentration; dose, $0.5 \mathrm{~mL} / \mathrm{kg}$ ). The scan direction was craniocaudal, and the scan range was from the inlet of the thorax to $2 \mathrm{~cm}$ below the diaphragm level. A nonionic contrast agent (iopamidol, $370 \mathrm{mg} / \mathrm{mL}$; Bracco, Italy) was given intravenously $(1.5 \mathrm{~mL} / \mathrm{kg}$ body weight) at a rate of $1.2-2.5 \mathrm{~mL} / \mathrm{s}$, followed by $20 \mathrm{~mL}$ of saline solution. Automated bolus-tracking software was utilized to start the scan when the region of interest attenuation threshold reached $100 \mathrm{HU}$ following a delay of $5 \mathrm{~s}$. The protocol parameters (flash chest pain electrocardiogram; ECG) were as follow: tube voltage (80-120 kV; controlled 
by CARE KV), CARE Dose 4D (used to reduce the tube current), gantry rotation time $(0.28 \mathrm{~s})$, and pitch (0.2-0.5; adapted to heart rate). Moreover, the field of view was adjusted to body size.

Images were reconstructed with a slice thickness and an increment of 0.75 and $0.5 \mathrm{~mm}$, respectively. The convolution kernel was $126 \mathrm{f}$ medium smooth ASA. Sinogram-affirmed iterative reconstruction (strength, 3) and a retrospective ECG-gated technique were used to improve image quality. All image data were transferred to a workstation (Syngo; Siemens Medical Systems, Forchheim, Germany). Several postprocessing methods (e.g., multiplanar reformations, volume rendering, and maximum intensity projection) were applied to complete image analysis (16).

\section{Image analysis}

All DSCT images were retrospectively reviewed by two veteran radiologists without knowing the surgery or DSA results. The main abnormalities were carefully reviewed at the workstation using different postprocessing methods. The diameters of the left pulmonary arterials, right pulmonary arterials, MACAPs, and descending aorta were recorded similarly to that in reference (16). The only difference in the measurement was that the main pulmonary arterial (MPA) if existing was located at the maximum of MPA. All measurements avoided narrow places. The body surface area was calculated by the Stevenson formula. The McGoon ratio, pulmonary arterials index (PAI), and total neopulmonary arterial index (TNPAI) were calculated in the standard ways.

The echocardiographic images were performed by an experienced cardiac ultrasound radiologist and checked by another senior radiologist. All detected malformations were recorded from long and short cardiac axis view at the xiphoid process, parasternum, and suprasternal fossa. The aortopulmonary window level was used to detect the collateral circulation.

\section{Radiation dose estimation}

DSCT examinations strictly adhered to the principle of "as low as reasonably achievable". Tube voltage, tube current, and pitch were adjusted on the basis of every patient's individual circumstance to lower the dose as much as possible as illustrated above. Volume CT dose index (CTDI ${ }_{\text {vol }}$ ) and dose length product (DLP) were recorded. Patients of different ages reacted differently to the radiation dose. Hence, the effective dose (ED) with different conversion coefficients was calculated as $k(E D=D L P \times k)$ on the basis of the 2007 recommendations of the International Commission on Radiological Protection $(18,19)$.

\section{Statistical analysis}

The Statistical Package for the Social Sciences software for Windows (version 25.0, SPSS Inc., Chicago, IL, USA) was used for statistical analysis. The Shapiro-Wilk test was used to test the normality of the variables. Bartlett's test was used to assess the homogeneity of the variance. Categorical variables were 
measured as percentages and compared by Fisher's exact or chi-square test, depending on the expected frequencies. Continuous variables were recorded as mean values or medians and were compared by oneway analysis of variance (ANOVA) followed by least-significant difference (LSD) post hoc test (normally distributed continuous variables and the variance is homogeneous) or the Kruskal-Wallis test (nonnormally distributed continuous variables). The interobserver reproducibility of McGoon ratio, TPI, and TNPAI was tested by intraclass correlation coefficient (ICC) by using 32 randomly chosen patients. The ICC score of $>0.75$ was taken for satisfactory agreement. ANOVA followed by LSD post hoc test was used to compare subgroups of PA. Furthermore, a two-tailed $p$ value of $<0.05$ was considered statistically significant in all statistical analyses.

\section{Results}

\section{Baseline characteristics of all patients with PA}

This study consecutively included 73 (female, $41 ; 56.2 \%$ ) patients. The mean age was $27(8.6-62.5)$ months (range, 19 days -35 years old). The mean body mass index and heart rate were 15.2 (13.7-17.4) $\mathrm{kg} / \mathrm{m}^{2}$ and $117 \pm 19 \mathrm{bpm}$, respectively. Furthermore, the mean preoperative and postoperative $\mathrm{SpO}_{2}$ was $79.3 \pm 10.5 \%$ and $94.7 \%(84.0 \%-97.0 \%)$ (if patients underwent operation), respectively.

\section{Basic characteristics and surgical indices among three subgroups}

Of the patients, 29, 29, and 15 were divided into the groups of PA/VSD/MAPCAs (Fig. 1-3), PA/VSD (Fig. 4), and the PA group with other major malformations (i.e., six patients with a double outlet of the right ventricle, two patients with SV, two patients with SV and SA, one patient with SV and mitral valve atresia, and three patients with intact ventricle (Fig. 5)), respectively. For basic clinical characteristics, most indices showed no significant difference except for age and respiratory rate. For quantitative parameters that are of guiding significance for surgical options, McGoon ratio and PAI were significantly different among the three groups ( $p=0.027$ and $p=0.035$, respectively). However, McGoon and TNPAI showed no significant difference between PA/VSD/MAPCAs and PA patients with other major malformations. Table 1 shows more detailed information regarding the three groups. 
Table 1

Baseline characteristics of three groups

\begin{tabular}{|c|c|c|c|c|}
\hline Characteristics & $\begin{array}{l}\text { PA/VSD } \\
(n=29)\end{array}$ & $\begin{array}{l}\text { PAVSD/MAPCAs } \\
(n=29)\end{array}$ & $\begin{array}{l}\text { PA with other major } \\
\text { malformation } \\
(n=15)\end{array}$ & $\begin{array}{l}P \\
\text { values }\end{array}$ \\
\hline Age, months & $\begin{array}{l}10.8(5.0-43 . \\
0) *\end{array}$ & $\begin{array}{l}54.0(23.5- \\
110.0)^{*}\end{array}$ & $21.0(12.0-51.0)$ & 0.000 \\
\hline Male, n (\%) & $10(33.3)$ & $13(44.8)$ & $9(60.0)$ & 0.229 \\
\hline $\mathrm{BMI}\left(\mathrm{kg} / \mathrm{m}^{2}\right)$ & $\begin{array}{l}15.6(14.0- \\
17.4)\end{array}$ & $14.9(13.6-18.5)$ & $14.1(13.6-15.6)$ & 0.566 \\
\hline Heart rate (bpm) & $122 \pm 20$ & $112 \pm 20$ & $116 \pm 12$ & 0.125 \\
\hline $\begin{array}{l}\text { Respiratory rate } \\
(\mathrm{bpm})\end{array}$ & $29 \pm 6^{*}$ & $25 \pm 3 * \S$ & $29 \pm 5^{\S}$ & 0.003 \\
\hline $\begin{array}{l}\text { Preoperative } \mathrm{SpO}_{2} \\
(\%)\end{array}$ & $77.1 \pm 11.7$ & $82.1 \pm 9.6$ & $78.3 \pm 9.0$ & 0.138 \\
\hline $\begin{array}{l}\text { Postoperative } \mathrm{SpO}_{2} \\
(\%)\end{array}$ & $\begin{array}{l}94.8(87.0- \\
96.2)\end{array}$ & $95.6(81.0-97.2)$ & $86.1(82.5-95.0)$ & 0.289 \\
\hline Heart murmurs, $\mathrm{n}(\%)$ & $26(89.7)$ & $27(93.1)$ & $14(93.3)$ & 0.254 \\
\hline \multicolumn{5}{|l|}{ Symptoms, n (\%) } \\
\hline Cyanosis & $25(86.2)$ & $22(75.9)$ & $15(100)$ & 0.278 \\
\hline $\begin{array}{l}\text { Post-exercising } \\
\text { tachypnea }\end{array}$ & $9(31.0)$ & $12(41.4)$ & $4(26.7)$ & 0.280 \\
\hline Cold-ridden & $8(27.6)$ & $6(20.7)$ & $4(26.7)$ & 0.829 \\
\hline Growth retardation & $6(20.7)$ & $7(24.1)$ & $5(33.3)$ & 0.727 \\
\hline Squatting & $6(20.7)$ & $4(13.8)$ & 0 & 0.181 \\
\hline Acropachy & $2(6.9)$ & $4(13.8)$ & 0 & 0.306 \\
\hline Dyspnea & $2(6.9)$ & $4(13.8)$ & $1(6.7)$ & 0.686 \\
\hline No symptom & $4(13.8)$ & $3(10.3)$ & $1(6.7)$ & 0.896 \\
\hline Treatments, n (\%) & & & & 0.041 \\
\hline
\end{tabular}

Values are means (standard deviations or $\mathrm{n}(\%)$ ). $\mathrm{P}$ value was the result of ANOVA analysis among three groups, or the result of Student's t test/Chi-square/ Fisher's exact test between subgroups. * means $p<0.05$ between PA/VSD and PA/VSD/MAPCAs; $\S$ means $p<0.05$ between PA with other major anomalies and PA/VSD/MAPCAs.

Abbreviations: PAl, pulmonary arterials index; TNPAl, total neopulmonary arterial index 


\begin{tabular}{|c|c|c|c|c|}
\hline Characteristics & $\begin{array}{l}\text { PAVSD } \\
(n=29)\end{array}$ & $\begin{array}{l}\text { PAVSD/MAPCAs } \\
(n=29)\end{array}$ & $\begin{array}{l}\text { PA with other major } \\
\text { malformation } \\
(n=15)\end{array}$ & $\begin{array}{l}P \\
\text { values }\end{array}$ \\
\hline Staged surgery & $17(58.6)$ & $10(34.5)$ & $9(60.0)$ & \\
\hline One-staged surgery & $12(41.4)$ & $13(44.8)$ & $4(26.7)$ & \\
\hline DSA only & 0 & $6(20.7)$ & $2(13.3)$ & \\
\hline McGoon & $1.73 \pm 0.50^{*}$ & $1.34 \pm 0.59^{*}$ & $1.55 \pm 0.43$ & 0.027 \\
\hline PAl & $\begin{array}{l}201.75 \pm \\
115.19^{*}\end{array}$ & $133.28 \pm 104.00^{\star \S}$ & $212.19 \pm 111.85^{\S}$ & 0.035 \\
\hline TNPAI & - & $223.81 \pm 128.65$ & $193.10 \pm 65.62$ & 0.579 \\
\hline \multicolumn{5}{|c|}{$\begin{array}{l}\text { Values are means (standard deviations or } n(\%) \text { ). P value was the result of ANOVA analysis among } \\
\text { three groups, or the result of Student's test/Chi-square/ Fisher's exact test between subgroups. * } \\
\text { means } p<0.05 \text { between PA/VSD and PA/VSD/MAPCAs; } \$ \text { means } p<0.05 \text { between PA with other } \\
\text { major anomalies and PA/VSD/MAPCAs. }\end{array}$} \\
\hline
\end{tabular}

\section{The quantitative parameters comparison among different treatments groups}

Of the patients, 36 and 29 underwent or prepared to undergo multiple-stage surgeries and one-stage surgery (Fig. 6), respectively, and eight were inoperable after DSA examination. The quantitative parameters were not significant among the different treatments group (Table 2). All ICC scores were > 0.75 , showing great repeatability (Table 3 ).

Table 2

The quantitative parameters among 3 different treatment groups

\begin{tabular}{|lllll|}
\hline Index & Multiple-Staged surgeries & One-staged surgery & DSA only & P values \\
\hline McGoon & $1.56 \pm 0.57$ & $1.66 \pm 0.51$ & $1.11 \pm 0.50$ & 0.084 \\
\hline PAl & $186.83 \pm 123.23$ & $183.31 \pm 113.13$ & $131.29 \pm 69.95$ & 0.550 \\
\hline TNPAl & $224.06 \pm 119.54$ & $236.75 \pm 153.54$ & $191.68 \pm 74.85$ & 0.736 \\
\hline Abbreviations: PAl, pulmonary arterials index; TNPAl, total neopulmonary arterial index. \\
\hline
\end{tabular}


Table 3

The ICC scores of two radiologists

\begin{tabular}{|lllll|}
\hline Index & Radiologist 1 & Radiologist 2 & ICC & $95 \% \mathbf{C l}$ \\
\hline McGoon & $1.53 \pm 0.53$ & $1.51 \pm 0.60$ & 0.943 & $0.885-0.972$ \\
\hline PAl & $171.90 \pm 105.60$ & $167.56 \pm 114.50$ & 0.969 & $0.938-0.985$ \\
\hline TNPAl & $174.87 \pm 69.18$ & $168.31 \pm 78.20$ & 0.947 & $0.825-0.985$ \\
\hline Abbreviations: PAl, pulmonary arterials index; TNPAl, total neopulmonary arterial index.
\end{tabular}

\section{Comparison between TEE and DSCT for diagnosing intracardiac or extracardiac anomalies}

Of the anomalies, 178, 144, and 12 intracardiac, extracardiac, and other major anomalies were diagnosed (Table 4). DSCT showed a better diagnostic performance in extracardiac anomalies (137 vs 100, $p=$ 0.000 ), whereas TEE could diagnose intracardiac anomalies better (158 vs 134, $p=0.001$ ). For other major anomalies, TEE and DSCT did not show a significant difference $(p=0.667)$. Moreover, DSCT could demonstrate cardiac vessels better than TEE, especially PDA and MAPCAs. The sensitivity for PDA and MAPCAs were $90.0 \%$ (DSCT) vs $92.0 \%$ (TTE) and $94.6 \%$ (DSCT) vs $81.1 \%$ (TTE), respectively. While, the specificity were $82.6 \%$ (DSCT) vs $39.1 \%$ (TTE) and $100 \%$ vs $81.1 \%$, respectively. TTE could diagnose valve anomalies better, including valve malformation and valvular inadequacy. The sensitivity and specificity were $88.2 \%$ (TTE) vs $29.4 \%$ (DSCT) and $98.2 \%$ (TTE) vs $100 \%$ (DSCT), respectively (Table 5). 
Table 4

All malformation diagnosed by TTE, DSCT and final diagnoses $(n=73)$

Tape of malformation

Final diagnoses

DSCT diagnoses

TTE diagnoses

$\begin{array}{llllllll}\text { TP } & \text { TN } & \text { FP } & \text { FN } & \text { TP } & \text { TN } & \text { FP } & \text { FN }\end{array}$

Intra-cardiac anomalies

\begin{tabular}{|c|c|c|c|c|c|c|c|c|c|}
\hline VSD & 68 & 66 & 5 & 2 & 0 & 67 & 3 & 2 & 1 \\
\hline ASD/PFO & 50 & 27 & 23 & 0 & 23 & 41 & 18 & 5 & 9 \\
\hline Aorta overriding & 43 & 36 & 22 & 8 & 7 & 35 & 25 & 5 & 8 \\
\hline Valve abnormities & 17 & 5 & 56 & 0 & 12 & 15 & 55 & 1 & 2 \\
\hline DROV & 6 & 3 & 65 & 2 & 3 & 4 & 64 & 3 & 2 \\
\hline \multicolumn{10}{|c|}{ Extra-cardiac anomalies } \\
\hline PDA & 50 & 45 & 19 & 4 & 5 & 46 & 9 & 14 & 4 \\
\hline MAPCAs & 37 & 35 & 36 & 0 & 2 & 30 & 7 & 6 & 30 \\
\hline RAA & 22 & 22 & 50 & 1 & 0 & 14 & 48 & 3 & 8 \\
\hline DAA & 2 & 2 & 71 & 0 & 0 & 0 & 71 & 0 & 2 \\
\hline PSVC & 13 & 13 & 58 & 2 & 0 & 6 & 59 & 1 & 7 \\
\hline ASA & 11 & 11 & 61 & 1 & 0 & 0 & 62 & 0 & 11 \\
\hline CAA & 8 & 8 & 64 & 1 & 0 & 3 & 64 & 6 & 0 \\
\hline SV & 4 & 3 & 68 & 1 & 1 & 4 & 69 & 0 & 0 \\
\hline$S V+S A$ & 2 & 1 & 72 & 0 & 1 & 1 & 72 & 0 & 1 \\
\hline PAPVC & 1 & 1 & 72 & 0 & 0 & 1 & 71 & 1 & 0 \\
\hline
\end{tabular}

Abbreviations: TP, true positive finding; FN, false negative finding; TN, true negative finding; FP, false positive finding; VSD, ventricular septal defect; ASD, atrial septal defect; DROV, double outlet right ventricle; PDA, patent ductus arteriosus; MAPCAs, major aortopulmonary collateral arterials; RAA, right aortic arch; DAA, double aortic arch; PSVC, persistent superior vena cava, ASA, aberrant subclavian artery, CAA, coronary artery anomalies; SV, single ventricle; SA, single atrium; PAPVC, partial anomalous pulmonary venous connection. 
Table 5

The diagnostic accuracy of DSCT and TTE $(n=73)$

\section{Type of malformation DSCT diagnoses}

TTE diagnoses

$\begin{array}{llllllll}\text { sen } & \text { spe } & \text { ppv } & \text { npv } & \text { sen } & \text { spe } & \text { ppv } & \text { npv } \\ (\%) & (\%) & (\%) & (\%) & (\%) & (\%) & (\%) & (\%)\end{array}$

Intra-cardiac

anomalies

\begin{tabular}{lllllllll} 
VSD & 100 & 71.4 & 95.7 & 100 & 95.7 & 60 & 97.1 & 75 \\
\hline ASD/PFO & 54.0 & 100 & 100 & 50.0 & 82.0 & 78.3 & 89.1 & 66.6 \\
\hline Aorta overriding & 83.7 & 81.8 & 73.3 & 75.9 & 81.4 & 83.3 & 87.5 & 75.8 \\
\hline Valve abnormities & 29.4 & 100 & 100 & 82.4 & 88.2 & 98.2 & 93.8 & 96.5 \\
\hline DROV & 50.0 & 97.0 & 60.0 & 95.6 & 66.7 & 95.5 & 57.1 & 97.0
\end{tabular}

Extra-cardiac

anomalies

\begin{tabular}{lllllllll} 
PDA & 90.0 & 82.6 & 91.8 & 79.2 & 92.0 & 39.1 & 76.7 & 69.2 \\
\hline MAPCAs & 94.6 & 100 & 100 & 94.7 & 81.1 & 53.8 & 83.3 & 18.9 \\
\hline RAA & 100 & 98.0 & 95.7 & 100 & 63.6 & 94.1 & 82.4 & 85.7 \\
\hline DAA & 100 & 100 & 100 & 100 & 0 & 100 & 0 & 97.3 \\
\hline PSVC & 100 & 96.7 & 86.7 & 100 & 46.2 & 98.3 & 85.7 & 89.4 \\
\hline ASA & 100 & 98.4 & 91.7 & 100 & 0 & 84.9 & 0 & 84.9 \\
\hline CAA & 100 & 98.5 & 88.9 & 100 & 60 & 91.4 & 33.3 & 100 \\
\hline SV & 75.0 & 98.6 & 75.0 & 98.6 & 100 & 100 & 100 & 100 \\
\hline SV + SA & 50.0 & 100 & 100 & 98.6 & 50.0 & 100 & 100 & 98.6 \\
\hline PAPVC & 100 & 100 & 100 & 100 & 100 & 98.6 & 50 & 100
\end{tabular}

Abbreviations: Sen sensitivity, Spec specificity, PPV positive predictive value, NPV negative predictive value. VSD: ventricular septal defect; ASD: atrial septal defect; DROV: double outlet right ventricle; PDA: patent ductus arteriosus; MAPCAs: major aortopulmonary collateral arterials; RAA: right aortic arch; DAA: double aortic arch; PSVC: persistent superior vena cava; ASA: aberrant subclavian artery; CAA: coronary artery anomalies; SV: single ventricle; SA: single atrium; PAPVC: partial anomalous pulmonary venous connection.

\section{Radiation dose estimation}

The DLP and CTDI ${ }_{\mathrm{vol}}$ of the different groups are classified by age (Table 6). The ED were $1.61 \pm 0.39,0.97$ $\pm 0.43,0.87 \pm 0.37,0.73 \pm 0.22$, and $1.53 \pm 0.76 \mathrm{mSv}$ in patients $<4$ months, $4-12$ months, $1-5$ years, $5-$ 
10 years, and $>10$ years, respectively.

Table 6

Radiation dose estimation in different age groups

\begin{tabular}{|llllll|}
\hline & $<4$ months & $\begin{array}{l}\mathbf{4} \text { months } \\
\text { to } \mathbf{1} \text { year }\end{array}$ & $\begin{array}{l}\mathbf{1} \text { year to } \\
\mathbf{5} \text { years }\end{array}$ & $\begin{array}{l}\mathbf{5} \text { years to } \\
\mathbf{1 0} \text { years }\end{array}$ & $\begin{array}{l}\mathbf{1 0} \text { years } \\
\text { to adults }\end{array}$ \\
\hline Patients, $\mathrm{n}(\%)$ & $7(9.6)$ & $18(24.7)$ & $31(42.5)$ & $11(15.1)$ & $7(9.6)$ \\
\hline CTDIvol (mGy) & $7.49 \pm 2.49$ & $8.81 \pm 3.75$ & $9.10 \pm 5.09$ & $7.32 \pm 2.49$ & $9.45 \pm 4.41$ \\
\hline DLP (mGy.cm) & $33.57 \pm 15.88$ & $37.11 \pm 16.69$ & $47.81 \pm 19.98$ & $50.82 \pm 22.61$ & $109.14 \pm 54.41$ \\
\hline ED (mSv) & $1.61 \pm 0.39$ & $0.97 \pm 0.43$ & $0.87 \pm 0.37$ & $0.73 \pm 0.22$ & $1.53 \pm 0.76$ \\
\hline Abbreviations: CTDIvol, volume CT dose index; DLP, dose-length product; ED, effective dose. \\
\hline
\end{tabular}

\section{Discussion}

PA is a complex CHD accompanied by different intracardiac or extracardiac anomalies. The treatments are diverse in different anomalies $(11,12)$. Hence, an accurate preoperative diagnosis is of great importance for patient treatment and management. This study has major discoveries. (1) Different groups of PA patients have different surgical indices (McGoon ratio, PAl, and TNPAI) and DSCT can demonstrate NPA and MAPCAs well. Therefore, the surgical indices could be roughly calculated to design treatments. (2) DSCT has a better diagnostic performance for extracardiac anomalies than that of TTE.

Patients in this study were classified into three groups according to their major anomalies. Most studies only focused on one type of PA, that is, PA/VSD, PA/VSD/MAPCAs, or PA/IVS (20). and it is believed that no study comparing different types of PA currently exists. Additionally, only a few studies showed the values of low dose DSCT in patients with PA. The results of this study showed that the common clinical data were not significantly different except for age and respiratory rate. However, all these data indicated that patients were in a poor situation. For example, preoperative $\mathrm{SpO}_{2}$ is low and symptoms are obvious and critical. This may be explained by the fact that PA is a complex and severe CHD which makes them in poor situation. Meanwhile, most patients in the three groups were able to undergo surgical treatments meaning that they were in the same poor situation to some extent. By contrast, the surgical indices (McGoon ratio and PAI), as well as various treatments among the three groups, was significantly different.

PA/VSD had a higher McGoon ratio and PAl. Moreover, all patients underwent surgical treatments. The other two groups had a lower McGoon ratio and PAI. Consequently, more patients only underwent DSA examinations or palliative surgery. Different McGoon ratios and PAI indicate the development of the NPA situation. A higher ratio means a lower risk of surgery and better outcome $(21,22)$. Thus, patients with 
low surgical indices could not undergo the one-stage surgery, which helps to explain the fact that more patients in the two latter groups did not undergo one-stage surgery in this study. However, TNPAl was not significant in the latter two groups, which may be because of the small sample size (only six patients had MAPCAs in the group of PA with other major malformation). DSCT could depict NPA and MAPCAs well and display them in three dimensions with the help of postprocessing techniques. Thus, their diameter could be roughly measured. On the basis of this fact, surgical plan could be roughly designed. Moreover, DSCT could show the stenosis places and the concrete origin locations of MAPCAs which are important for the surgical plan of patients with PA/VSD/MAPCAs. This study demonstrates the value of DSCT used to design the treatment plans without undergoing DSA. DSA can be used to assess the situation of NPA, MAPACs and the pulmonary blood supply(23). But it is invasive and expensive. What's more, DSA with the highest patient radiation dose has an insurmountable defect for infants and children because they are more vulnerable to radiation(24).

Compared with echocardiography, DSCT demonstrates extracardiac anomalies better, while TTE diagnoses intracardiac anomalies (especially valve anomalies) better in this study, which is consistent with the previous studies $(25,26)$. Complex congenital heart diseases often accompanied by not only intracardiac malformation but also extracardiac malformation which need more than one imaging modalities to get a correct diagnosis. TTE is the routine examination for heart diseases, especially for $\mathrm{CHD}$, which could investigate the intracardiac anomalies and hemodynamics well. However, TTE is not very useful for extracardiac anomalies for its limited acoustic window and is dependent on the operators heavily(27). DSA is identified as "gold standard" for the blood supply of the lungs. But it also has some shortcomings as illustrated above. Cardiac MRI can measure hemodynamics, either. But it is not often applied to CHD for it is demanding for motionlessness and time which is difficult for young patients and patients with CHD. Besides, cardiac MRI also has little contribution to pulmonary artery measurement (28).

All of these insufficiencies can be complemental by DSCT. With the development of DSCT, it has increasingly been applied to CHD. It can portray the extra-cardiac anomalies well and provide more mediastinal anatomy information for surgeon to design surgical plans before the operation owing to its high density resolution and powerful postprocessing techniques. Moreover, its high temporal resolution enables its use in patients with high heart rate (29) by using two independent X-ray tubes and corresponding detectors. Additionally, as our results shows, its radiation dose has been reduced to as low as reasonably achievable (14), which makes it suitable for young patients. Thus, DSCT plays an irreplaceable role in the diagnosis of PA and treatment and management design.

Several limitations exist in this study. First, all patients came from a single center, which leads to selection bias and a relatively small sample size, especially for the group of PA with other major malformation, which influenced the data collection and analysis of this study. Hence, further studies with larger samples coming from multicenter should be conducted. Second, the radiation dose has reduced greatly, although still existing, which helps reduce the injury for young patients, with the help of technique 
development. Third, the outcomes of the different groups with long-term follow-up, which may aid in further management of this disease, were not tracked.

\section{Conclusion}

$\mathrm{PA}$ is a rare and fatal type of heterogeneous $\mathrm{CHD}$. More than one imaging modality should be used to make a correct diagnosis when clinically suspecting PA. TTE can diagnose intracardiac anomalies well, whereas DSCT can demonstrate extracardiac malformation better and give more information to optimize the surgical design.

\section{Declarations}

\section{Funding}

This study has received funding by 1.3 .5 project for disciplines of excellence, West China Hospital, Sichuan University (ZYGD18013) and Sichuan Science and Technology Program (2020YJ0229). The funding sources had no role of the study design; collection; analysis and interpretation of data; in the writing of the report; and in the decision to submit the article for publication.

\section{Conflicts of interest/Competing interests}

The authors declare that they have no conflict of interest.

\section{Availability of data and material}

All data and material used in this study are included in this manuscript.

\section{Authors' contributions}

QWL participated in the study design, data collection, performed the statistical analysis, and drafted the manuscript. YZG contributed to study design, and contributed to preparation, editing and review of the manuscript. ZXZ participated in the study design, data collection, and contributed to quality control of data and analysis, and editing and review of the manuscript. SK and JL contribute to preparation of the manuscript. SLT participated in data acquisition and analysis. All authors read and approved the final manuscript.

\section{Ethics approval}


This study was approved by the Institutional Ethics Committee of West China Hospital, Sichuan University (Chengdu, Sichuan, China), with a waiver of informed consent due to the retrospective nature.

\section{Consent for publication}

Not applicable

\section{Acknowledgements}

Not applicable

\section{References}

1. Kawel N, Valsangiacomo-Buechel E, Hoop R, Kellenberger CJ. Preoperative evaluation of pulmonary artery morphology and pulmonary circulation in neonates with pulmonary atresia-usefulness of MR angiography in clinical routine. Journal of cardiovascular magnetic resonance: official journal of the Society for Cardiovascular Magnetic Resonance. 2010 Sep 15;12(1):52. PubMed PMID: 20843357. Pubmed Central PMCID: PMC2950013. Epub 2010/09/17. eng.

2. Tchervenkov $\mathrm{Cl}$, Roy N. Congenital Heart Surgery Nomenclature and Database Project: pulmonary atresia-ventricular septal defect. The Annals of thoracic surgery. 2000 Apr;69(4 Suppl):S97-105. PubMed PMID: 10798421. Epub 2000/05/08. eng.

3. Hu BY, Shi K, Deng YP, Diao KY, Xu HY, Li R, et al. Assessment of tetralogy of Fallot-associated congenital extracardiac vascular anomalies in pediatric patients using low-dose dual-source computed tomography. BMC cardiovascular disorders. 2017 Dec 4;17(1):285. PubMed PMID: 29202750. Pubmed Central PMCID: PMC5715549. Epub 2017/12/06. eng.

4. Zhao QM, Liu F, Wu L, Ma XJ, Niu C, Huang GY. Prevalence of Congenital Heart Disease at Live Birth in China. The Journal of pediatrics. 2019 Jan;204:53-8. PubMed PMID: 30270157. Epub 2018/10/03. eng.

5. Leonard H, Derrick G, O'Sullivan J, Wren C. Natural and unnatural history of pulmonary atresia. Heart (British Cardiac Society). 2000 Nov;84(5):499-503. PubMed PMID: 11040008. Pubmed Central PMCID: PMC1729492. Epub 2000/10/20. eng.

6. Soquet J, Barron DJ, d'Udekem Y. A Review of the Management of Pulmonary Atresia, Ventricular Septal Defect, and Major Aortopulmonary Collateral Arteries. The Annals of thoracic surgery. 2019 Aug;108(2):601 - 12. PubMed PMID: 30831109. Epub 2019/03/05. eng.

7. Bull K, Somerville J, Ty E, Spiegelhalter D. Presentation and attrition in complex pulmonary atresia. Journal of the American College of Cardiology. 1995 Feb;25(2):491-9. PubMed PMID: 7829805. Epub 1995/02/01. eng. 
8. Thiene G, Frescura C, Bini RM, Valente M, Gallucci V. Histology of pulmonary arterial supply in pulmonary atresia with ventricular septal defect. Circulation. 1979 Nov;60(5):1066-74. PubMed PMID: 487540. Epub 1979/11/01. eng.

9. Liao PK, Edwards WD, Julsrud PR, Puga FJ, Danielson GK, Feldt RH. Pulmonary blood supply in patients with pulmonary atresia and ventricular septal defect. Journal of the American College of Cardiology. 1985 Dec;6(6):1343-50. PubMed PMID: 4067114. Epub 1985/12/01. eng.

10. Reddy VM, McElhinney DB, Amin Z, Moore P, Parry AJ, Teitel DF, et al. Early and intermediate outcomes after repair of pulmonary atresia with ventricular septal defect and major aortopulmonary collateral arteries: experience with 85 patients. Circulation. 2000 Apr 18;101(15):1826-32. PubMed PMID: 10769284. Epub 2000/04/19. eng.

11. Mi YP, Chau AK, Chiu CS, Yung TC, Lun KS, Cheung YF. Evolution of the management approach for pulmonary atresia with intact ventricular septum. Heart (British Cardiac Society). 2005 May;91(5):657-63. PubMed PMID: 15831657. Pubmed Central PMCID: PMC1768866. Epub 2005/04/16. eng.

12. Mainwaring RD, Patrick WL, Roth SJ, Kamra K, Wise-Faberowski L, Palmon M, et al. Surgical algorithm and results for repair of pulmonary atresia with ventricular septal defect and major aortopulmonary collaterals. The Journal of thoracic and cardiovascular surgery. 2018 Sep;156(3):1194-204. PubMed PMID: 29789151. Epub 2018/05/24. eng.

13. Han BK, Rigsby CK, Hlavacek A, Leipsic J, Nicol ED, Siegel MJ, et al. Computed Tomography Imaging in Patients with Congenital Heart Disease Part I: Rationale and Utility. An Expert Consensus Document of the Society of Cardiovascular Computed Tomography (SCCT): Endorsed by the Society of Pediatric Radiology (SPR) and the North American Society of Cardiac Imaging (NASCl). Journal of cardiovascular computed tomography. 2015 Nov-Dec;9(6):475 - 92. PubMed PMID: 26272851. Epub 2015/08/15. eng.

14. Shi K, Yang ZG, Xu HY, Zhao SX, Liu X, Guo YK. Dual-source computed tomography for evaluating pulmonary artery in pediatric patients with cyanotic congenital heart disease: Comparison with transthoracic echocardiography. European journal of radiology. 2016 Jan;85(1):187-92. PubMed PMID: 26724664. Epub 2016/01/03. eng.

15. Koplay M, Kizilca O, Cimen D, Sivri M, Erdogan H, Guvenc O, et al. Prospective ECG-gated high-pitch dual-source cardiac CT angiography in the diagnosis of congenital cardiovascular abnormalities: Radiation dose and diagnostic efficacy in a pediatric population. Diagnostic and interventional imaging. 2016 Nov;97(11):1141-50. PubMed PMID: 27156243. Epub 2016/05/09. eng.

16. Yin L, Lu B, Han L, Wu RZ, Johnson L, Xu ZY, et al. Quantitative analysis of pulmonary artery and pulmonary collaterals in preoperative patients with pulmonary artery atresia using dual-source computed tomography. European journal of radiology. 2011 Sep;79(3):480-5. PubMed PMID: 20627639. Epub 2010/07/16. eng.

17. Chaosuwannakit N, Makarawate P. The value of dual-source multidetector-row computed tomography in determining pulmonary blood supply in patients with pulmonary atresia with 
ventricular septal defect. Folia morphologica. 2018;77(1):116-22. PubMed PMID: 28703845. Epub 2017/07/14. eng.

18. Deak PD, Smal Y, Kalender WA. Multisection CT protocols: sex- and age-specific conversion factors used to determine effective dose from dose-length product. Radiology. 2010 Oct;257(1):158-66. PubMed PMID: 20851940. Epub 2010/09/21. eng.

19. The 2007 Recommendations of the International Commission on Radiological Protection. ICRP publication 103. Annals of the ICRP. 2007;37(2-4):1-332. PubMed PMID: 18082557. Epub 2007/12/18. eng.

20. Cohen J, Binka E, Woldu K, Levasseur S, Glickstein J, Freud LR, et al. Myocardial strain abnormalities in fetuses with pulmonary atresia and intact ventricular septum. Ultrasound in obstetrics \& gynecology: the official journal of the International Society of Ultrasound in Obstetrics and Gynecology. 2019 Apr;53(4):512-9. PubMed PMID: 30043402. Pubmed Central PMCID: PMC6353696. Epub 2018/07/26. eng.

21. Nakata S, Imai Y, Takanashi Y, Kurosawa H, Tezuka K, Nakazawa M, et al. A new method for the quantitative standardization of cross-sectional areas of the pulmonary arteries in congenital heart diseases with decreased pulmonary blood flow. The Journal of thoracic and cardiovascular surgery. 1984 Oct;88(4):610-9. PubMed PMID: 6482493. Epub 1984/10/01. eng.

22. Karaca-Altintas $Y$, Laux D, Gouton $M$, Bensemlali $M$, Roussin $R$, Hörer $J$, et al. Nakata index above $1500 \mathrm{~mm} 2 / \mathrm{m} 2$ predicts death in absent pulmonary valve syndrome. European journal of cardiothoracic surgery: official journal of the European Association for Cardio-thoracic Surgery. 2020 Jan 1;57(1):46-53. PubMed PMID: 31180449. Epub 2019/06/11. eng.

23. Reddy VM, Petrossian E, McElhinney DB, Moore P, Teitel DF, Hanley FL. One-stage complete unifocalization in infants: when should the ventricular septal defect be closed? The Journal of thoracic and cardiovascular surgery. 1997 May;113(5):858-66; discussion 66 - 8. PubMed PMID: 9159619. Epub 1997/05/01. eng.

24. Bacher K, Bogaert E, Lapere R, De Wolf D, Thierens H. Patient-specific dose and radiation risk estimation in pediatric cardiac catheterization. Circulation. 2005 Jan 4;111(1):83 - 9. PubMed PMID: 15611374. Epub 2004/12/22. eng.

25. Mei M, Nie J, Yang ZS, Sun HW, Wang H, Kang XM. Comparison of echocardiography and 64-slice spiral computed tomography in the diagnosis of congenital heart disease in children. Journal of cellular biochemistry. 2019 Mar;120(3):3969-77. PubMed PMID: 30321464. Epub 2018/10/16. eng.

26. Zhao Q, Wang J, Yang ZG, Shi K, Diao KY, Huang S, et al. Assessment of intracardiac and extracardiac anomalies associated with coarctation of aorta and interrupted aortic arch using dualsource computed tomography. Scientific reports. 2019 Aug 12;9(1):11656. PubMed PMID: 31406129. Pubmed Central PMCID: PMC6690938. Epub 2019/08/14. eng.

27. Novaes JY, Zamith MM, Araujo Júnior E, Barreto EQ, Barros FS, Moron AF. Screening of Congenital Heart Diseases by Three-Dimensional Ultrasound Using Spatiotemporal Image Correlation: Influence 
of Professional Experience. Echocardiography (Mount Kisco, NY). 2016 Jan;33(1):99-104. PubMed PMID: 26096717. Epub 2015/06/23. eng.

28. Dacher JN, Barre E, Durand I, Hazelzet T, Brasseur-Daudruy M, Blondiaux É, et al. CT and MR imaging in congenital cardiac malformations: Where do we come from and where are we going? Diagnostic and interventional imaging. 2016 May;97(5):505 - 12. PubMed PMID: 27012158. Epub 2016/03/26. eng.

29. Flohr TG, McCollough $\mathrm{CH}$, Bruder $\mathrm{H}$, Petersilka $\mathrm{M}$, Gruber $\mathrm{K}$, Süss $\mathrm{C}$, et al. First performance evaluation of a dual-source CT (DSCT) system. European radiology. 2006 Feb;16(2):256 - 68. PubMed PMID: 16341833. Epub 2005/12/13. eng.

\section{Figures}
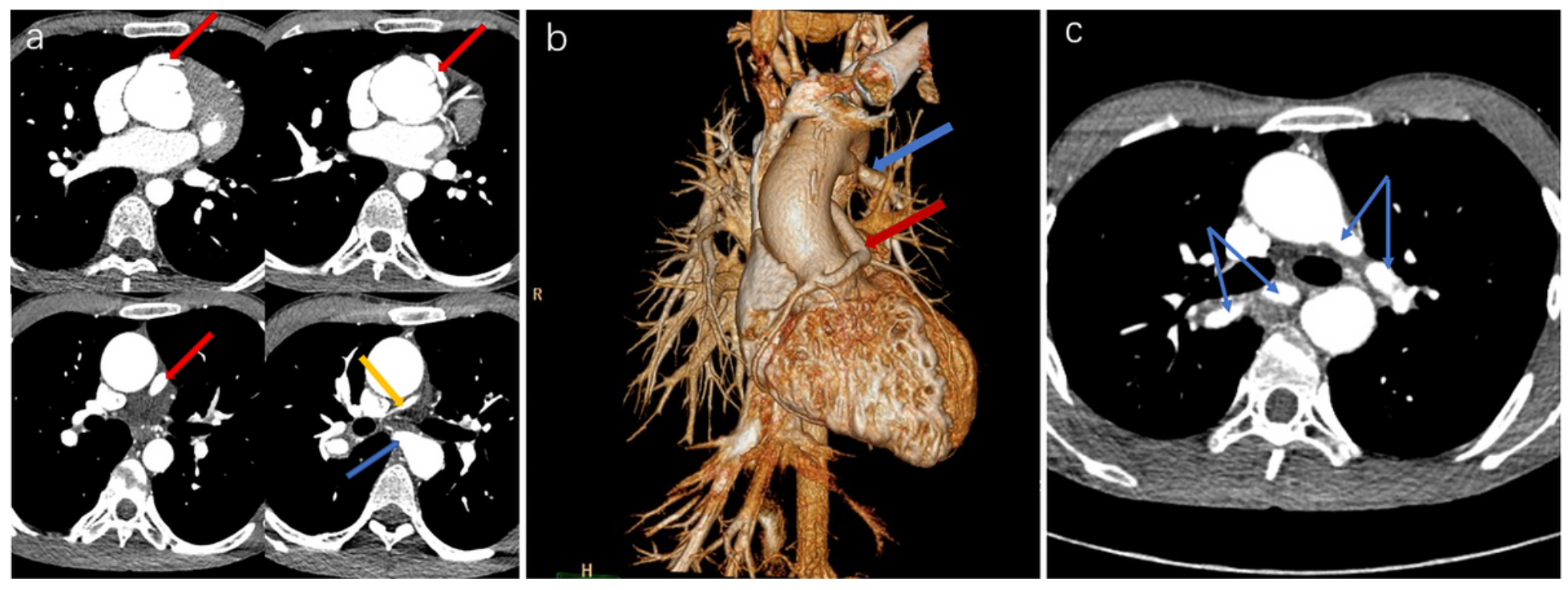

Figure 1

A pulmonary atresia (PA) patient with ventricular septal defect (VSD) and major aortopulmonary collateral arteries (MAPCAs) A source of the blood supply of his right lung came from the right coronary artery (CA, red arrows). His right pulmonary artery (yellow arrow) and left pulmonary artery (not shown) developed poor, leading to MAPCAs growing (blue arrows). a. the transverse image of the right coronary artery and one of MAPCAs. b. The volume rendering (VR) of the CA and a MAPCA. c. the MAPCAs supply blood for the lungs. 

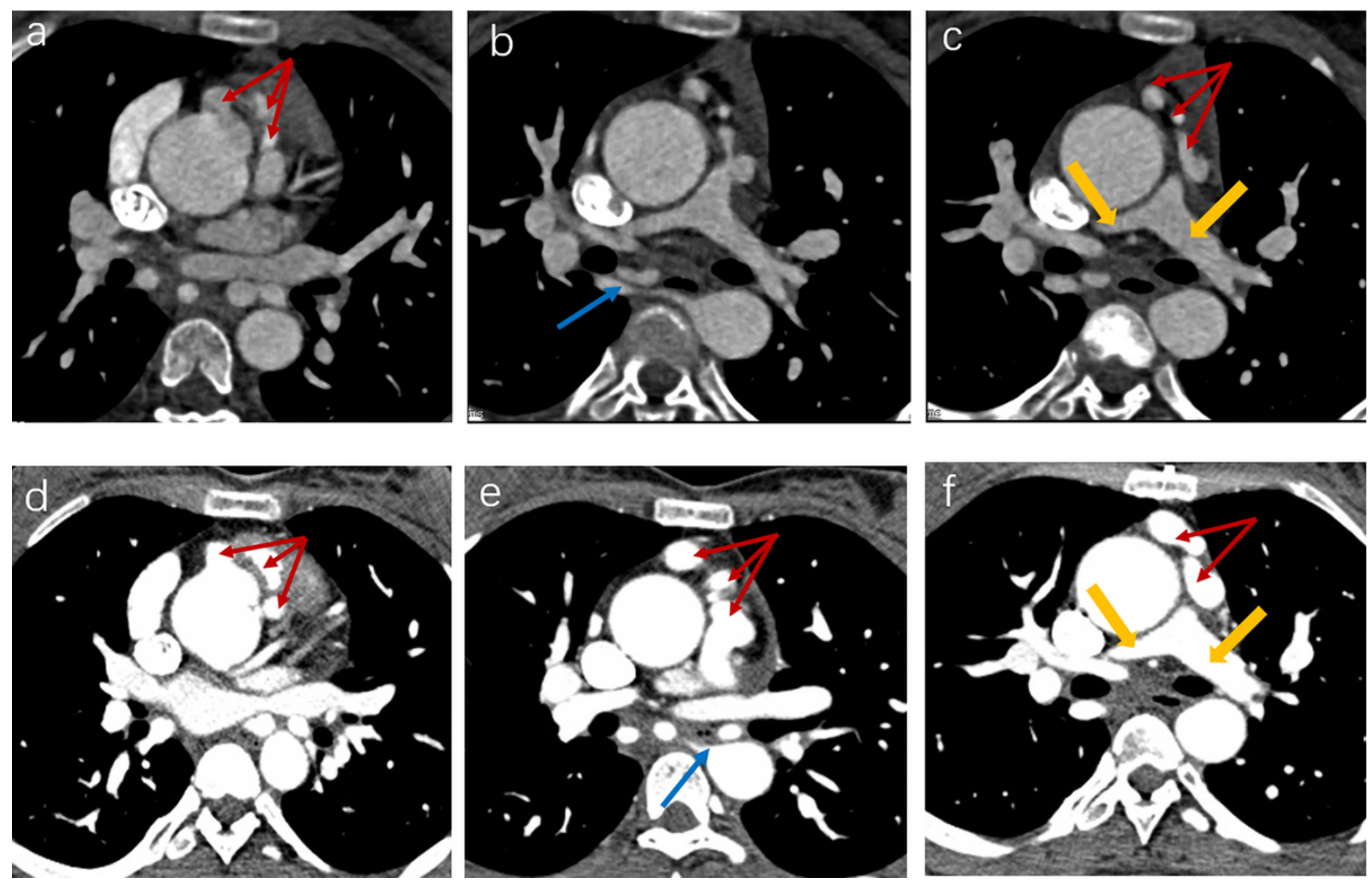

Figure 2

Two sets of images of a PA/VSD/ MAPCAs patients Images of a-c were captured in 2013 and d-f were taken in 2019. Unlike with the patient in figure 1, the blood supply of this patient lungs depended more on right CA (red arrows) than MAPCA (blue arrows). After six years, the right CA dilated more distinct, while the left/ right pulmonary artery (yellow arrows) and MAPCA changed little. 

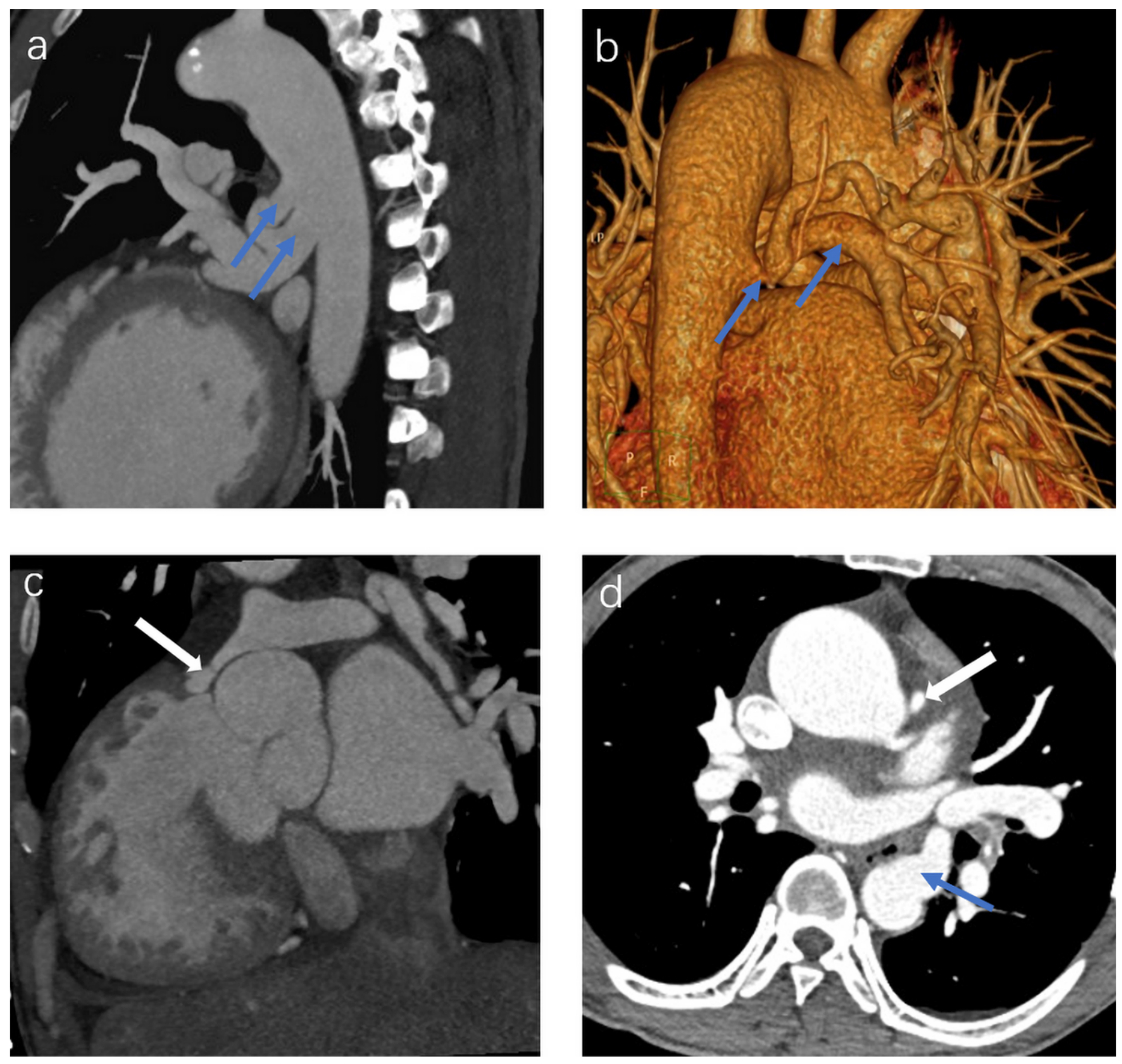

\section{Figure 3}

The images of an adult PA/VSD/MAPCAs a. The reconstruction image of his MAPCAs (blue arrows). $b$. The VR image of the MAPCAs. c. The reconstruction of the PA. There is no connection between right ventricle and pulmonary trunk (white arrow). $d$. the transverse images of pulmonary and one of MAPCAs. abbreviation: Ao: aorta 

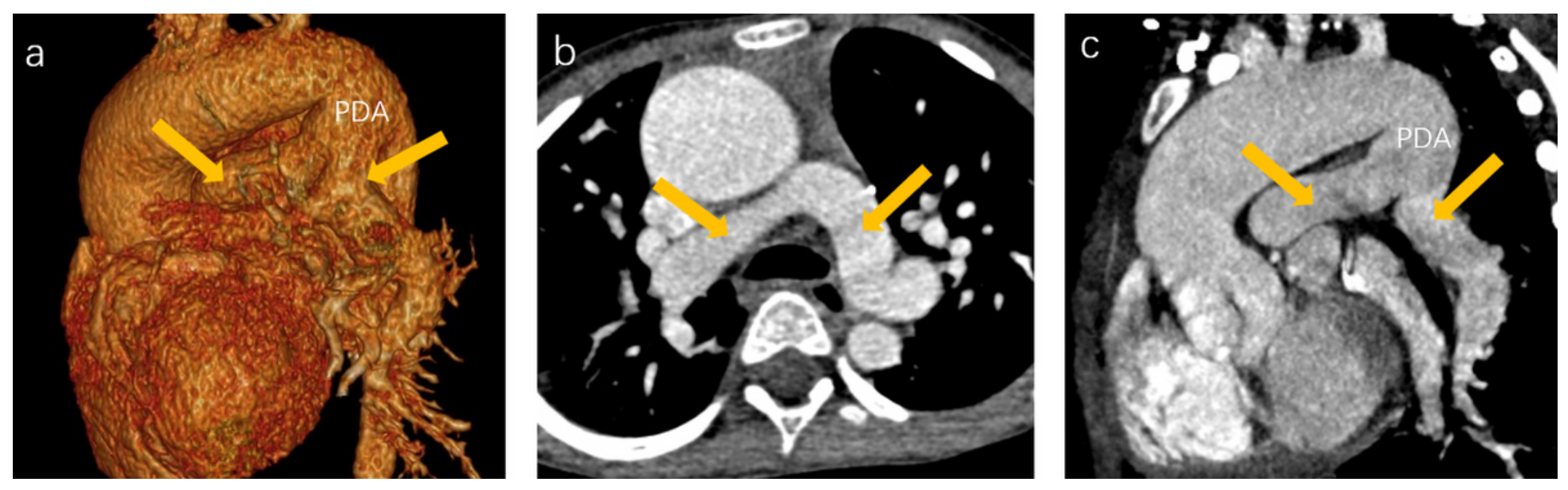

Figure 4

A patient with PA/VSD The blood supply of his lungs came from patent ductus arteriosus (PDA). His ascending aorta and aortic arch dilated obviously. His PDA was tube-shaped and his left/ right pulmonary artery (yellow arrows) developed well. a. the VR image of PDA and left/right pulmonary. b. the transverse image of left/right pulmonary. c. the reconstruction image of PDA and left/right pulmonary.
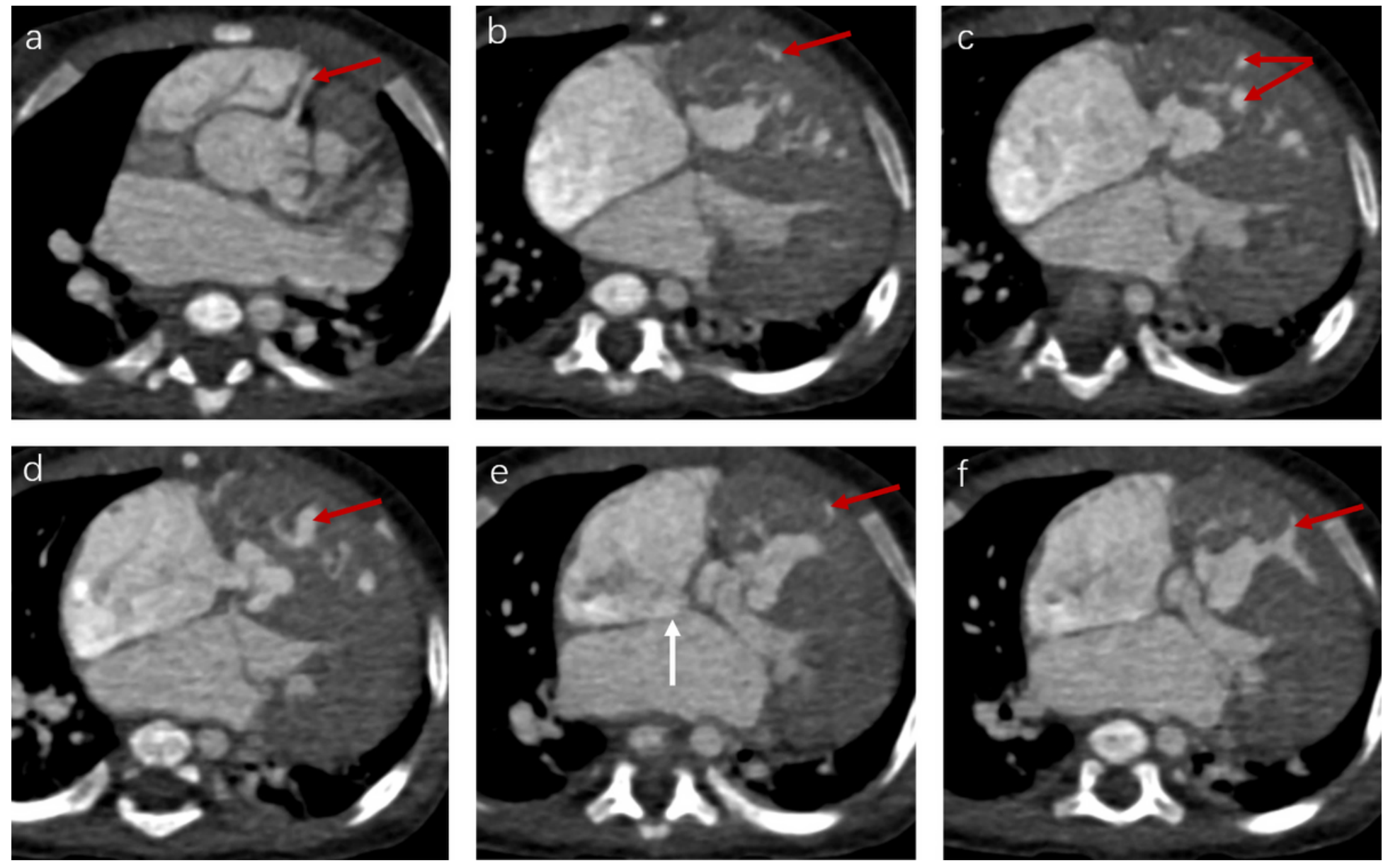

Figure 5

The images of a PA patient with intact ventricular septum (IVS) complicated by right ventricular dependent coronary circulation (RVDCC) PA/IVS/RVDCC is a rare and fatal type of PA whose treatments 
is different with other types of PA. The tricuspid valve and right ventricle of this patient developed poorly. Besides, he had atrial septal defect (white arrow). The red arrows show that the right CA communicates with the right ventricle.
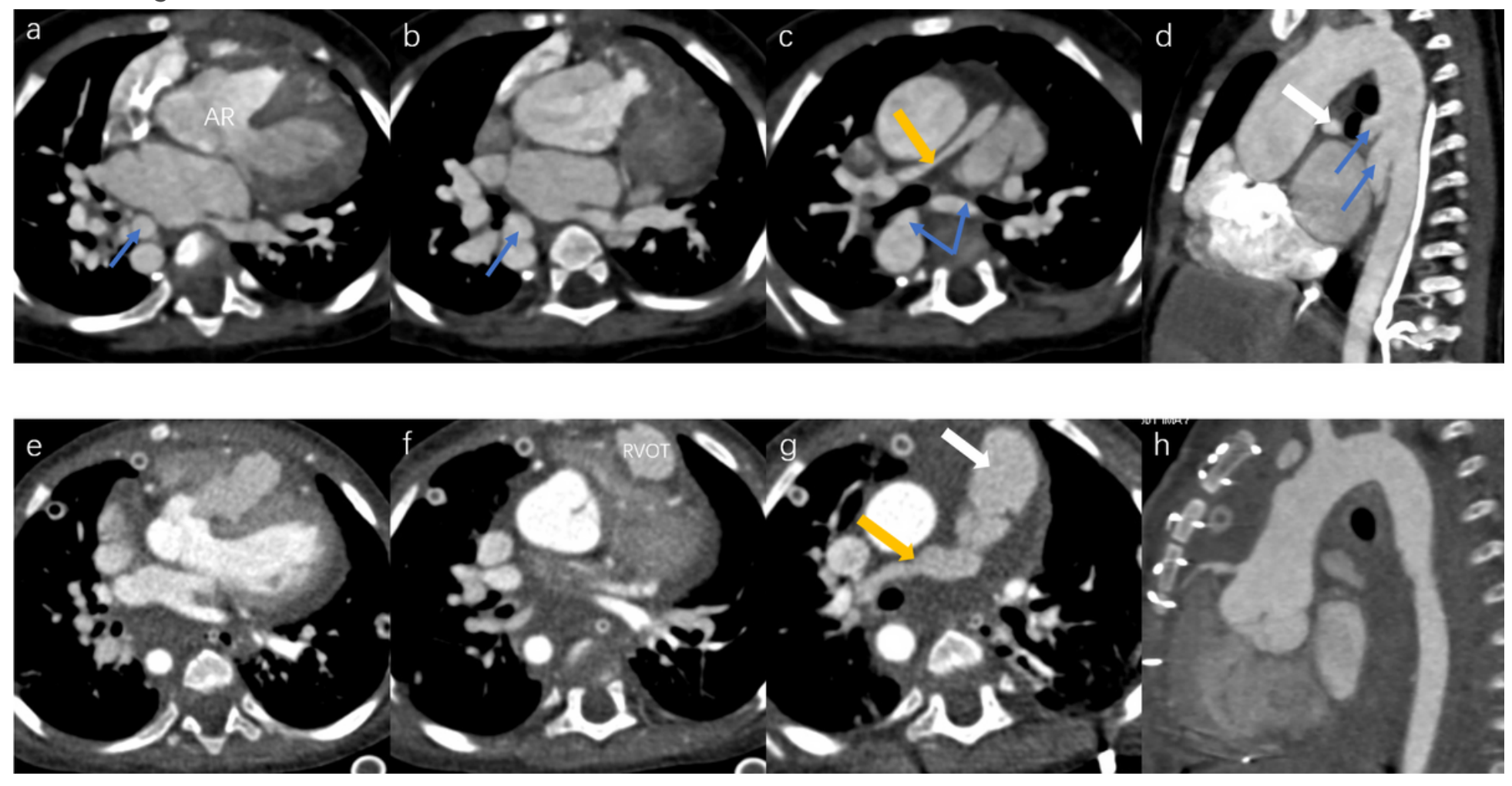

Figure 6

Two sets images of a PA patient who underwent surgery The images of a-d were pre-operation and e-h were post-operation. The surgery reconstructed the right ventricular outflow tract (ROVT) and pulmonary trunk (white arrow), repaired the aortic riding (AR), disconnected the MAPCAs (blue arrows) and expanded the right pulmonary artery (yellow arrow) and left pulmonary artery (not shown) by using the disconnected MAPCAs. This patient was accompanied with right aortic arch. 